\title{
Air pollution and DNA methylation: effects of exposure in humans
}

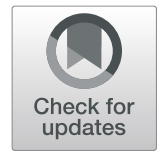

Christopher F. Rider ${ }^{1,2^{*}}$ (D) and Chris Carlsten ${ }^{1,2,3,4}$

\begin{abstract}
Air pollution exposure is estimated to contribute to approximately seven million early deaths every year worldwide and more than $3 \%$ of disability-adjusted life years lost. Air pollution has numerous harmful effects on health and contributes to the development and morbidity of cardiovascular disease, metabolic disorders, and a number of lung pathologies, including asthma and chronic obstructive pulmonary disease (COPD). Emerging data indicate that air pollution exposure modulates the epigenetic mark, DNA methylation (DNAm), and that these changes might in turn influence inflammation, disease development, and exacerbation risk. Several traffic-related air pollution (TRAP) components, including particulate matter $(\mathrm{PM})$, black carbon $(\mathrm{BC})$, ozone $\left(\mathrm{O}_{3}\right)$, nitrogen oxides $\left(\mathrm{NO}_{x}\right)$, and polyaromatic hydrocarbons (PAHs), have been associated with changes in DNAm; typically lowering DNAm after exposure. Effects of air pollution on DNAm have been observed across the human lifespan, but it is not yet clear whether early life developmental sensitivity or the accumulation of exposures have the most significant effects on health. Air pollution exposure-associated DNAm patterns are often correlated with long-term negative respiratory health outcomes, including the development of lung diseases, a focus in this review. Recently, interventions such as exercise and B vitamins have been proposed to reduce the impact of air pollution on DNAm and health. Ultimately, improved knowledge of how exposure-induced change in DNAm impacts health, both acutely and chronically, may enable preventative and remedial strategies to reduce morbidity in polluted environments.
\end{abstract}

Keywords: Epigenetics, 5-Methylcytosine, Epidemiology, Controlled human exposure studies, Diesel exhaust

\section{Introduction}

Air pollution is well known to be harmful to health, and emerging data support the hypothesis that exposure to air pollution may contribute to the development of lung conditions, metabolic disorders, and cardiovascular disease [1]. While there are acute effects of exposure to air pollutants, we do not understand if exposures during gestation or childhood have a greater impact on disease development than those experienced as an adult, or if morbidity is simply driven by the accumulation of exposures. In addition to health effects, exposure to air pollution can alter epigenetic marks, in particular, DNA methylation (DNAm). However, our understanding of how air pollution modulates DNAm in the lungs and

\footnotetext{
* Correspondence: crider@ubc.ca

${ }^{1}$ Respiratory Medicine, Faculty of Medicine, Chan-Yeung Centre for

Occupational and Environmental Respiratory Disease (COERD), University of

British Columbia, Vancouver, British Columbia, Canada

²Diamond Health Care Centre 7252, 2775 Laurel Street, Vancouver, BC V5Z 1

M9, Canada

Full list of author information is available at the end of the article
}

beyond, and how these changes in DNAm influence the associated health outcomes, remains modest. Studies suggest that air pollution exposure often results in a widespread decrease in DNAm, but we do not understand whether such effects are targeted to specific sites or scattered across the genome globally due to untargeted effects on epigenetic control mechanisms. Here, we review the in vivo effects of air pollution exposure on DNAm and briefly discuss the association of DNAm with lung health in humans.

\section{Air pollution}

Air pollution is a complex mixture of particulate matter and gasses that are produced by multiple industrial, commercial, and individual activities [2-4]. Traffic-related air pollution (TRAP) is a significant source in urban environments, especially of particulate matter (PM), which includes black carbon (BC), absorbed metals, and polyaromatic hydrocarbons (PAHs) of various size fractions, the smallest of which can penetrate deep into the 
lungs $[3,5]$. TRAP also includes gasses, such as nitrogen oxides (e.g., $\mathrm{NO}_{2}, \mathrm{NO}_{x}$ ) and sulfur dioxide $\left(\mathrm{SO}_{2}\right)$. The interaction of $\mathrm{NO}_{2}$ and PAHs with heat and sunlight results in the formation of highly reactive ground-level ozone $\left(\mathrm{O}_{3}\right)$ [6]. Individual components of air pollution mixtures are rarely encountered in isolation within natural settings, which makes attribution to particular elements challenging outside of single-source or component controlled human exposure studies [7, 8].

Owing to its complex composition, the mechanisms involved in the health effects of air pollution are not entirely clear and could include direct oxidative effects of $\mathrm{O}_{3}$ or induction of reactive oxygen species (ROS) following PM exposure. The oxidative stress induced by exposures mediates activation of downstream inflammatory pathways, such as mitogen-activated protein kinase (MAPK), nuclear factor-kappa B (NF-kB) and activator protein 1 (AP1), leading to increased cytokine expression, activation of immune cells, and ultimately inflammation. Epigenetic mechanisms may also contribute to the development and maintenance of inflammation and conditions such as asthma [9-11]. Epigenetic mechanisms include changes in histone tail modifications, miRNA expression, and DNAm.

\section{DNA methylation}

DNAm describes the attachment of methyl groups to DNA, usually at the fifth carbon of cytosines, leading to the formation of 5-methylcytosine (5-mC) [12]. In mammals, DNAm predominantly occurs at C-G dinucleotides, referred to as CpGs. Only approximately $1 \%$ of bases and $5 \%$ of cytosines across the genome are methylated, but $60-80 \%$ of CpGs are methylated in individual human somatic cells [13]. Though controversial, DNAm in the promoter regions of genes may contribute, along with histone variants, histone modifications, and non-coding RNAs, to the regulation of gene expression [11, 12]. CpGs are sparsely and non-randomly distributed in much of the genome, but gene promoter regions often contain "CpG islands" which consist of areas of approximately $1 \mathrm{~kb}$ enriched with $\mathrm{CpG}$ sites and flanked on either side by regions known as "CpG shores" and then by "CpG shelves" [14]. Un- or sparsely methylated promoter CpG islands are correlated with active gene expression and are often located near constitutively expressed housekeeping genes, while methylated $\mathrm{CpG}$ island promoters may be associated with reduced expression of the proximal gene $[12,14,15]$. DNAm of CpG sites located in gene bodies may be related to transcription initiation, elongation efficiency, and alternative splicing $[16,17]$.

\section{DNA methylation and demethylation}

DNAm is driven and maintained by the activity of DNA methyltransferases (DNMT) (Fig. 1) [16, 18]. The methyl groups needed are transferred from S-adenosyl methionine (SAMe), which is generated by members of the methionine adenosyltransferase (MAT) enzyme family as part of the one-carbon cycle [12, 16]. DNA demethylation occurs passively through a lack of maintenance during cell division or by the activity of enzymes, including ten-eleven translocation methylcytosine dioxygenase (TET) family members. TETs convert 5-mC to 5-hydroxymethylcytosine (5-hmC) and then to 5-formylcytosine (5-fC) and finally 5carboxycyotosine $(5-\mathrm{caC})$, along with other related conversions (Fig. 1) [12, 13, 16]. Finally, G/T mismatch-specific thymine-DNA glycosylase (TDG) excises 5 -fC or 5-caC and restores an unmethylated cytosine through excision repair $[13,19] .5-\mathrm{mC}$ can also be deaminated to uracil, which can be restored to cytosine again via excision repair [19].

\section{Measuring DNA methylation}

DNAm is often assessed through bisulphite conversion of DNA, though other techniques use high-performance liquid chromatography, mass spectrometry, antibodies or proteins that bind methylated DNA, or methylation-sensitive restriction enzymes [20,21]. With bisulphite conversion, 5 - $\mathrm{hmC}$ cannot be distinguished from $5-\mathrm{mC}$, but other techniques are capable of this distinction [20, 22]. The DNA bases 5-mC and 5-hmC have been shown to have different effects on gene transcription, and it may, therefore, be important to be able to differentiate these bases to further understand the relative impact they have on disease [23].

PCR and pyrosequencing techniques allow individual sites to be assessed with high accuracy and can be used to analyze specific gene regions or repetitive elements, including long interspersed nuclear element (LINE) 1 and Alu repeats, which are used (albeit imperfectly) as surrogates for global DNAm [12, 24]. Array-based methods, particularly the Illumina Infinium HumanMethylation 450K ( 450,000 CpGs) and HumanMethylationEPIC platform ( 850,000 CpGs), have dramatically increased the efficiency of throughput but, due to decreasing cost, next-generation bisulfite sequencing is becoming common, even though it poses its own analysis challenges $[25,26]$.

\section{Epidemiological, population, and controlled crossover study designs}

The effects of air pollution on DNAm have been investigated using several different study designs [27].

\section{Epidemiological-land use regression study design}

Many studies use an epidemiological study approach in which concentrations of specific air pollutants are estimated, using factors such as geography, traffic patterns, and fixed air pollution sensor data, to generate land use regression (LUR) models [28]. Volunteers are recruited 


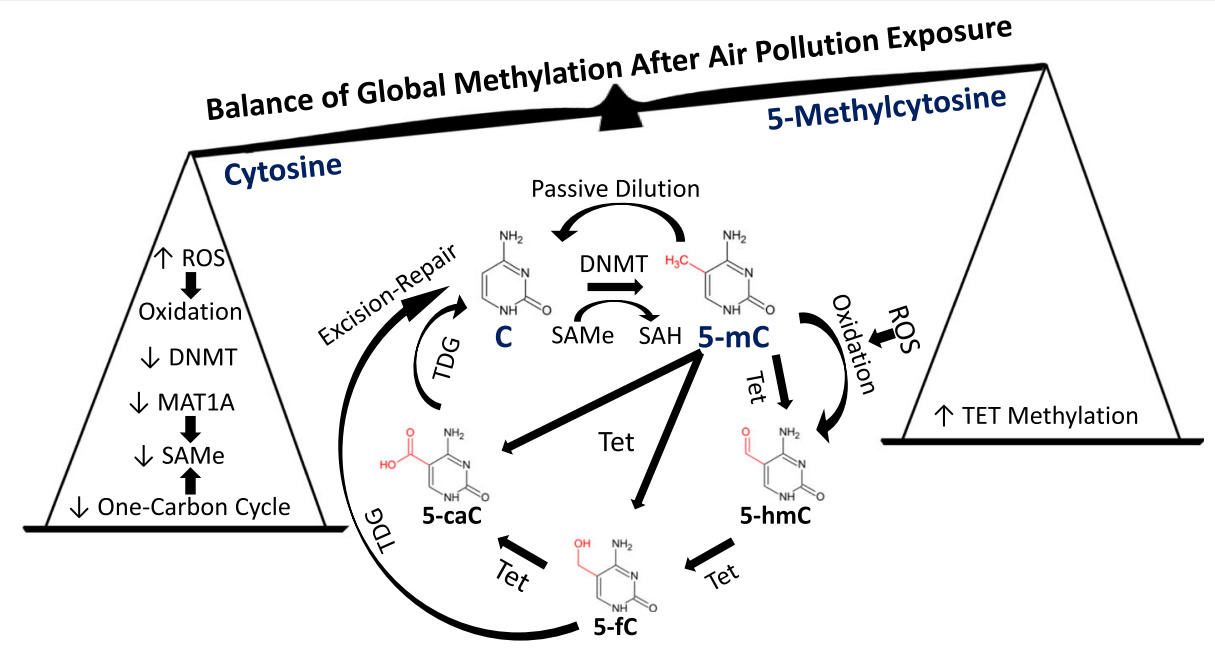

Fig. 1 Air pollution-associated effects that may modulate global DNA methylation. Cytosines (C) in CpG sites may be methylated to 5-methylcytosine (5-mC). Ten-eleven translocation methylcytosine dioxygenase (TET) family members can catalyze DNA demethylation through converting 5-mC to 5hydroxymethylcytosine (5-hmC), 5-formylcytosine (5-fC), and 5-carboxycyotosine (5-caC). G/T mismatch-specific thymine-DNA glycosylase (TDG) may as part of mismatch excision repair processes excise 5-fC or 5-caC and restore a $C$. Alternatively, 5-mC may undergo passive dilution and revert to $C$ during mitosis. Numerous factors could affect the balance of cytosine (C) and 5-methylcytosine (5-mC) at CpGs throughout the genome following air pollution exposure. Air pollution-induced reactive oxygen species (ROS) may increase oxidation of 5-mC to 5-hydroxymethylcytosine (5-hmC). Global generation of 5-mC may also be decreased by air pollution-induced reductions in DNA methyltransferase (DNMT) expression. Additionally, expression of methionine adenosyltransferase 1A (MAT1A) and activity of the one-carbon cycle may be lower, leading to reduced production of the methyl donor S-adenosyl methionine (SAMe) and subsequently 5-mC. Conversely, TET DNA methylation may reduce expression and subsequently decrease TET activity, which could contribute to maintaining $5-\mathrm{mC}$

and give samples (most often blood), and average air pollutant concentrations at each volunteer's home address are estimated using LUR models, over various time windows (usually 1, 3, 7, and 30 days) before their sample is collected [29-31]. Estimated average air pollution concentrations across multiple volunteers for each different time window are then correlated with data on global DNAm or methylation at specific CpG sites, with significance calculated from the fit of such correlations, and models adjusted for confounding factors. The health effects of exposures can then be investigated, provided that air pollution concentrations vary over time $[5,28$, 32]. This approach has the benefits of allowing realworld exposures to be studied but has several limitations, including difficulties in controlling for personal factors among volunteers, choosing the appropriate time window, and often not having a large concentration range within the study period $[27,28,31,32]$.

\section{Population study design}

An alternative to an epidemiological study approach is to compare people living in areas with different air pollution concentrations, for example, an area with lots of industry and high air pollution with a rural area nearby with low air pollution [27, 32-34]. After correction for differences between the populations living in these two locations, comparison allows estimation of the effects of the increased air pollution exposure associated with living in the industrial area. This study design has limitations, principally in matching characteristics of the volunteers living in the different regions, as there are, for example, often substantial wealth, education, and health care access disparities between areas with high and low air pollution [27, 32, 33, 35].

\section{Controlled crossover exposure studies}

In controlled crossover exposure studies, volunteers attend a facility where they are exposed to air pollution of a set concentration for a set time [27, 36, 37]. After a suitable washout period, volunteers return to the facility and receive an equivalent control exposure. By comparing the response to the control and air pollution exposure in each individual, across all the volunteers, the effects of the exposure can be accurately assessed. As each individual serves as their own control, the confounding effects of factors such as age and ethnicity are reduced [36, 38, 39]. However, such studies are difficult to implement, have considerable costs in terms of running facilities, and may be susceptible to carryover effects if washout periods are not sufficiently long. In summary, each of these experimental approaches has strengths and weaknesses, and there are therefore benefits to conducting multiple experiments using different methodologies to determine the effects of air pollution on DNAm. 


\section{Effects of air pollutants on DNA methylation across the life course}

DNAm data from different studies is measurable using standardized platforms and is reflective of transcription factor binding and gene expression. DNAm is, therefore, a logical tool for trying to understand air pollution's effect on genomic function and downstream measures of interest to health. Here, we outline research examining interactions between DNAm and air pollution, using a life stage approach [40].

\section{Effects of air pollution exposure in utero}

To understand whether in utero air pollution exposure affects DNAm, a number of studies have examined placenta or cord blood samples [33, 34, 41, 42]. One study showed a significant concentration-dependent association between exposure to $\mathrm{NO}_{2}$ during pregnancy and DNAm at three CpGs in cord blood samples measured using the Illumina 450K platform (Table 1 and Additional file 2: Table S2) [41]. The authors separately evaluated $739 \mathrm{CpGs}$ associated with 38 antioxidant and anti-inflammatory genes, identifying two differentially methylated genes, thyroid peroxidase (TPO) and catalase, which may have roles in responses to ROS. The association of $\mathrm{NO}_{2}$ exposure with $S L C 25 A 28$ and TPO DNAm was validated in blood samples from cohorts of 4- and 8year-old children [41]. $\mathrm{NO}_{2}$ is typically viewed as a surrogate for road traffic in outdoor city settings but is not necessarily independent of other TRAP-related exposures.

In a similar study in cord blood investigating exposure to $\mathrm{NO}_{x}$, none of the CpGs on the Illumina $450 \mathrm{~K}$ platform exceeded the cutoff, potentially reflecting the small sample size of the study [34]. Nevertheless, the CpGs with the smallest $p$ values in association with $\mathrm{NO}_{x}$ exposure were enriched within CpG islands, generally hypomethylated and included reduced DNAm of selenoprotein $\mathrm{K}$, an extracellular antioxidant that may contribute to exposure detoxification. These studies indicate that in utero exposure can significantly modulate DNAm, but that differences may be modest when changes in air pollution concentration are small, and therefore results may not pass correction for multiple testing [43]. Additionally, these results suggest that genes associated with the significantly modulated $\mathrm{CpG}$ sites may be related to oxidative stress pathways.

In addition to the gasses $\mathrm{NO}_{2}$ and $\mathrm{NO}_{x}$, in utero exposure to PM has also been shown to modulate DNAm. One of the most recent studies recruited 100 expectant mothers, 50 of whom lived in an area of elevated pollution $\left(\mathrm{PM}_{10} 80-111 \mu \mathrm{g} / \mathrm{m}^{3}, \mathrm{PM}_{2.5} 35-44 \mu \mathrm{g} / \mathrm{m}^{3}\right)$ and $50 \mathrm{in}$ a region with lower air pollution $\left(\mathrm{PM}_{10} 50-62 \mu \mathrm{g} / \mathrm{m}^{3}\right.$, $\mathrm{PM}_{2.5}$ 21-30 $\mu \mathrm{g} / \mathrm{m}^{3}$ ) (Table 1; Additional file 1: Table S1) [33]. There were significant changes in mean DNAm in placenta samples that positively correlated with $\mathrm{PM}_{2.5}$ and
$\mathrm{PM}_{10}$ exposure during the first trimester of pregnancy. These effects were surprising given that pollution levels appeared lowest on average (probably due to seasonal variation) during the first trimester of the study, indicating a potential period of enhanced vulnerability during early development. The existence of a period of early vulnerability is supported by another study in placental samples collected from 181 volunteers in China [44]. Higher PM $_{10}$ exposure during the first trimester, as assessed using LUR models developed from four fixed location sensors, was associated with lower LINE1 methylation. Indeed, each $10 \mu \mathrm{g} / \mathrm{m}^{3}$ increase in $\mathrm{PM}_{10}$ exposure, relative to the average of $\sim 64 \mu \mathrm{g} / \mathrm{m}^{3}$, was associated with a $1.78 \%$ decrease in LINE1 methylation. These results demonstrate that air pollution exposure in utero significantly modulates DNAm in a concentration-dependent manner and that the effects of the exposures remain detectable up to 6 months later in placental and cord blood samples collected at birth.

\section{Air pollution, DNA methylation, and growth restriction}

One common health outcome observed with prenatal exposure to air pollution is intrauterine growth restriction (IUGR), and this may be associated with higher air pollution sensitivity. In a study with case-control comparisons, more significant effects of air pollution on DNAm were found in babies with IUGR than those with healthy growth [44]. Another study showed that mothers living within $150 \mathrm{~m}$ of major roads, which had higher air pollution exposure, had babies with lower birth weight, along with lower placental LINE1 methylation and significant changes in DNAm at seven CpGs, compared to mothers living further from major roads (Additional file 2: Table S2) [42]. Although Maghbooli et al. showed higher mean DNAm after air pollution exposure, both Cai et al. and Kingsley et al. suggested that air pollution exposure reduced LINE1 methylation [33, 42, 44]. While the reasons behind this difference are unclear, relevant factors may include the differences between the study populations in China, the USA, and Iran, and between IUGR and normal babies, the use of pyrosequencing versus high-performance liquid chromatography analysis, the air pollution concentrations, and likely pollutant composition. As noted earlier, while LINE1 is often presented as a surrogate for global DNAm, it does so imprecisely relative to high-performance liquid chromatography analysis [24]. These results are relevant given the known associations between air pollution exposure and poor pregnancy outcomes, such as preterm birth [45].

Several possible mechanisms exist whereby DNAm might connect air pollution exposure to birth outcomes. In one study, placental hydroxysteroid 11-beta dehydrogenase 2 (HSD11B2) promoter methylation was higher by $1.03 \%$ and $2.23 \%$ in association with each $10 \mu \mathrm{g} / \mathrm{m}^{3}$ increase in $\mathrm{PM}_{10}$ exposure during the first and second 
Table 1 Detail on the studies reviewed. This table describes features of the studies described in this review, including the first author's surname, study location, detail on cohorts, volunteer number, sample types collected, and study details. NA not applicable, ND not determined, NR not reported, LINE long interspersed nuclear element, LUR land use regression. For additional details on the studies reviewed, please see Additional file 1: Table S1

\begin{tabular}{|c|c|c|c|c|c|c|c|}
\hline $\begin{array}{l}\text { Study } \\
\text { Author - } \\
\text { Year } \\
\end{array}$ & Cohorts & $\begin{array}{l}\text { Study } \\
\text { Location(s) }\end{array}$ & $\begin{array}{l}\text { Number } \\
\text { of } \\
\text { Volunteers }\end{array}$ & $\begin{array}{l}\text { Average } \\
\text { Age } \\
\text { (years) }\end{array}$ & Sample Type(s) & DNAm Analysis & Air Pollution Analysis \\
\hline \multicolumn{8}{|c|}{ In Utero Studies } \\
\hline \multirow{7}{*}{$\begin{array}{l}\text { Gruzieva } \\
2017\end{array}$} & MeDALL & Europe & 280 & 0 & Cord Blood & \multirow[t]{7}{*}{ Illumina $450 \mathrm{~K}$} & \multirow{7}{*}{$\begin{array}{l}\text { ESCAPE project } \\
\text { LUR } \mathrm{NO}_{2} \text { data }\end{array}$} \\
\hline & Generation R & Netherlands & 809 & 0 & Cord Blood & & \\
\hline & $\mathrm{CHS}$ & USA & 226 & 0 & Cord Blood & & \\
\hline & $\mathrm{MoBa}$ & Norway & 193 & 0 & Cord Blood & & \\
\hline & BAMSE & Sweden & 733 & 4.4 & Blood & & \\
\hline & MeDALL & Europe & 444 & 8.2 & Blood & & \\
\hline & BAMSE EpiGene & Sweden & 342 & 8.3 & Blood & & \\
\hline $\begin{array}{l}\text { Goodrich } \\
2016\end{array}$ & $\begin{array}{l}\text { Mother and Child } \\
\text { Environmental }\end{array}$ & $\begin{array}{l}\text { Durban, South } \\
\text { Africa }\end{array}$ & 22 & 26.1 & Cord Blood & Illumina $450 \mathrm{~K}$ & $\begin{array}{l}\mathrm{NO}_{x} \text { exposures } \\
\text { from LUR }\end{array}$ \\
\hline \multirow{2}{*}{$\begin{array}{l}\text { Maghbooli } \\
2018\end{array}$} & Low pollution area & \multirow[t]{2}{*}{ Tehran, Iran } & 44 & 30.09 & \multirow[t]{2}{*}{ Placenta } & \multirow[t]{2}{*}{ HPLC } & \multirow{2}{*}{$\begin{array}{l}\text { High and Low } \\
\text { Pollution Areas }\end{array}$} \\
\hline & $\begin{array}{l}\text { High pollution } \\
\text { area }\end{array}$ & & 48 & 30 & & & \\
\hline \multirow[t]{2}{*}{ Cai 2017} & Normal & Wenzhou, China & 101 & 26.7 & \multirow[t]{2}{*}{ Placenta } & \multirow[t]{2}{*}{ Pyrosequencing } & \multirow{2}{*}{$\begin{array}{l}\mathrm{PM}_{10} \text { from LUR } \\
\text { models }\end{array}$} \\
\hline & $\begin{array}{l}\text { Fetal Growth } \\
\text { Restriction }\end{array}$ & Wenzhou, China & 80 & 26.7 & & & \\
\hline $\begin{array}{l}\text { Kingsley } \\
2016\end{array}$ & $\begin{array}{l}\text { Rhode Island Child } \\
\text { Health Study }\end{array}$ & Providence, USA & 471 & 30 & Placenta & $\begin{array}{l}\text { Illumina } 450 \mathrm{~K} \\
\text { and } \\
\text { pyrosequencing }\end{array}$ & $\begin{array}{l}\text { Mothers categorized by } \\
\text { distance from highways }\end{array}$ \\
\hline \multicolumn{8}{|c|}{ Studies in Children } \\
\hline $\begin{array}{l}\text { Breton } \\
2016\end{array}$ & $\begin{array}{l}\text { Children's Health } \\
\text { Study }\end{array}$ & California, USA & 459 & 11.2 & Blood & Pyrosequencing & $\begin{array}{l}\text { LUR for } \mathrm{PM}_{2.5}, \mathrm{PM}_{10}, \\
\mathrm{NO}_{2} \text { and } \mathrm{O}_{3}\end{array}$ \\
\hline \multirow[t]{2}{*}{ Hew 2015} & \multirow[t]{2}{*}{ NA } & \multirow[t]{2}{*}{ Fresno, USA } & 171 & 13.7 & \multirow[t]{2}{*}{ Blood T regulatory cells } & \multirow[t]{2}{*}{ Pyrosequencing } & \multirow[t]{2}{*}{ LUR for PAH } \\
\hline & & & 85 & 15.1 & & & \\
\hline \multirow[t]{2}{*}{$\begin{array}{l}\text { Somineni } \\
2016\end{array}$} & $\begin{array}{l}\text { Exposure Sibling } \\
\text { Study for } \\
\text { discovery }\end{array}$ & Cincinnati, USA & 70 & 11 & \multirow{2}{*}{$\begin{array}{l}\text { Nasal Brushings } \\
\text { (validation in saliva, } \\
\text { PBMCs and bronchial } \\
\text { epithelial cells) }\end{array}$} & \multirow[t]{2}{*}{$\begin{array}{l}\text { Illumina } 450 \mathrm{~K} \\
\text { and } \\
\text { pyrosequencing }\end{array}$} & \multirow[t]{2}{*}{ LUR for black carbon } \\
\hline & $\begin{array}{l}\text { Pediatric } \\
\text { Environmental } \\
\text { Exposure Study } \\
\text { for replication }\end{array}$ & Cincinnati, USA & 186 & 12 & & & \\
\hline \multirow{2}{*}{$\begin{array}{l}\text { Lovinsky- } \\
\text { Desir } 2017\end{array}$} & Non-Active & \multirow[t]{2}{*}{ New York, USA } & 58 & 12.7 & \multirow{2}{*}{$\begin{array}{l}\text { Buccal swabs ( } 94 \% \\
\text { squamous epithelial } \\
\text { cells) }\end{array}$} & \multirow[t]{2}{*}{ Pyrosequencing } & \multirow{2}{*}{$\begin{array}{l}\text { BC assessed by vest } \\
\text { mounted monitors } \\
\text { and activity by accelerometer }\end{array}$} \\
\hline & Active & & 77 & 12.2 & & & \\
\hline \multicolumn{8}{|c|}{ Studies in Adults } \\
\hline Jiang 2014 & NA & $\begin{array}{l}\text { Vancouver, } \\
\text { Canada }\end{array}$ & 16 & 56 & Blood & Illumina $450 \mathrm{~K}$ & $\begin{array}{l}\text { Controlled exposures to } \\
\text { diesel exhaust and filtered air }\end{array}$ \\
\hline Bind 2014 & $\begin{array}{l}\text { Normative Aging } \\
\text { Study (NAS) }\end{array}$ & Boston, USA & 777 & 72 & Blood & Pyrosequencing & $\begin{array}{l}\mathrm{PM}_{2.5} \text {, particle number and } \mathrm{BC} \\
\text { assessed by LUR }\end{array}$ \\
\hline Bind 2015 & $\begin{array}{l}\text { Normative Aging } \\
\text { Study (NAS) }\end{array}$ & Boston, USA & 777 & 72 & Blood & Pyrosequencing & $\begin{array}{l}\mathrm{PM}_{2.5,} \text {, particle number and } \mathrm{BC} \\
\text { from LUR }\end{array}$ \\
\hline Lee 2017 & $\begin{array}{l}\text { Normative Aging } \\
\text { Study (NAS) }\end{array}$ & Boston, USA & 92 & ND & Blood & $\begin{array}{l}\text { Probably } \\
\text { pyrosequencing }\end{array}$ & $\mathrm{BC}$ and sulfate from LUR \\
\hline Chi 2016 & $\begin{array}{l}\text { Multi-Ethnic Study } \\
\text { of Atherosclerosis }\end{array}$ & $\begin{array}{l}\text { Baltimore, New } \\
\text { York, St. Paul, } \\
\text { Winston-Salem } \\
\text { USA }\end{array}$ & 1207 & 69.6 & PBMC & Illumina $450 \mathrm{~K}$ & $\begin{array}{l}\mathrm{PM}_{2.5} \text { and } \mathrm{NO}_{\mathrm{x}} \text { concentrations } \\
\text { from spatiotemporal models }\end{array}$ \\
\hline Panni 2016 & KORA F3 & Augsburg, & 500 & 53 & Blood & Illumina $450 \mathrm{~K}$ & $\mathrm{PM}_{2.5}$ exposures from LUR \\
\hline
\end{tabular}


Table 1 Detail on the studies reviewed. This table describes features of the studies described in this review, including the first author's surname, study location, detail on cohorts, volunteer number, sample types collected, and study details. NA not applicable, ND not determined, NR not reported, LINE long interspersed nuclear element, LUR land use regression. For additional details on the studies reviewed, please see Additional file 1: Table S1 (Continued)

\begin{tabular}{|c|c|c|c|c|c|c|c|}
\hline $\begin{array}{l}\text { Study } \\
\text { Author - } \\
\text { Year } \\
\end{array}$ & Cohorts & $\begin{array}{l}\text { Study } \\
\text { Location(s) }\end{array}$ & $\begin{array}{l}\text { Number } \\
\text { of } \\
\text { Volunteers }\end{array}$ & $\begin{array}{l}\text { Average } \\
\text { Age } \\
\text { (years) }\end{array}$ & Sample Type(s) & DNAm Analysis & Air Pollution Analysis \\
\hline & KORA F4 & Germany & 1799 & 61 & & & models \\
\hline & $\begin{array}{l}\text { Normative Aging } \\
\text { Study }\end{array}$ & Boston, USA & 657 & 72 & & & \\
\hline \multirow{2}{*}{$\begin{array}{l}\text { Mostafavi } \\
2017\end{array}$} & EPIC Italy Cohort & Italy & 95 & $\sim 50$ & PBMC & \multirow{2}{*}{$\begin{array}{l}\text { Agilent } 4 \times 44 \mathrm{~K} \\
\text { and Ilumina } \\
450 \mathrm{~K}\end{array}$} & \multirow[t]{2}{*}{$\mathrm{NO}_{x}$ estimated with LUR } \\
\hline & $\begin{array}{l}\text { Northern Swedish } \\
\text { Health and } \\
\text { Disease Study } \\
\text { Cohort }\end{array}$ & $\begin{array}{l}\text { Northern } \\
\text { Sweden }\end{array}$ & 455 & $\sim 50$ & PBMC & & \\
\hline \multirow{2}{*}{$\begin{array}{l}\text { Plusquin } \\
2017\end{array}$} & EPIC-Italy & Italy & 454 & 54.2 & \multirow[t]{2}{*}{ Blood } & \multirow[t]{2}{*}{ Illumina $450 \mathrm{~K}$} & \multirow{2}{*}{$\begin{array}{l}\mathrm{PM}_{10,}, \mathrm{PM}_{2.5,}, \mathrm{NO}_{2} \text { and } \mathrm{NO}_{x} \\
\text { from LUR models }\end{array}$} \\
\hline & EPIC-Netherlands & Netherlands & 159 & 58.8 & & & \\
\hline $\begin{array}{l}\text { De F.C. } \\
\text { Lichtenfels } \\
2018\end{array}$ & LifeLines & $\begin{array}{l}\text { Groningen, } \\
\text { Netherlands }\end{array}$ & 1017 & 47.3 & Blood & Illumina $450 \mathrm{~K}$ & $\begin{array}{l}\mathrm{NO}_{2}, \mathrm{PM}_{10}, \mathrm{PM}_{2.5} \text { from LUR } \\
\text { models }\end{array}$ \\
\hline $\begin{array}{l}\text { Mostafavi } \\
2018\end{array}$ & EXPOsOMICS & $\begin{array}{l}\text { Italy, } \\
\text { Netherlands, } \\
\text { Switzerland, } \\
\text { United Kingdom }\end{array}$ & 157 & 61 & Blood & Illumina $450 \mathrm{~K}$ & $\begin{array}{l}\text { PM2.5 assessed using } \\
\text { backpack sensor, outdoor } \\
\text { sensor and LUR model }\end{array}$ \\
\hline $\begin{array}{l}\text { Lepeule } \\
2014\end{array}$ & $\begin{array}{l}\text { Normative Aging } \\
\text { Study (NAS) }\end{array}$ & Boston, USA & 776 & 72 & Blood & Pyrosequencing & $\begin{array}{l}\mathrm{BC}, \mathrm{CO}, \mathrm{NO}_{2}, \mathrm{O}_{3} \text { and } \mathrm{PM}_{2.5} \\
\text { were modeled using LUR }\end{array}$ \\
\hline Peng 2016 & $\begin{array}{l}\text { Normative Aging } \\
\text { Study }\end{array}$ & Boston, USA & 551 & $\sim 76$ & Blood & Pyrosequencing & $\begin{array}{l}\text { PM2.5 assessed using a hybrid } \\
\text { LUR and satelite based model }\end{array}$ \\
\hline $\begin{array}{l}\text { Zhong } \\
2017\end{array}$ & NA & Toronto, Canada & 10 & $19-49$ & $\begin{array}{l}\text { CD4+ Th Cells }(\sim 96 \% \\
\text { pure) }\end{array}$ & Illumina $450 \mathrm{~K}$ & $\begin{array}{l}\text { Controlled exposures to } \\
\text { filtered air and concentrated } \\
\text { ambient } \mathrm{PM}_{2.5}\end{array}$ \\
\hline $\begin{array}{l}\text { De Nys } \\
2018\end{array}$ & NA & Leuven, Belgium & 23 & 22.3 & Buccal swabs & $\begin{array}{l}\text { UPLC - mass } \\
\text { spectrometry }\end{array}$ & $\mathrm{PM}_{2.5}$ and $\mathrm{PM}_{10}$ from LUR \\
\hline $\begin{array}{l}\text { Clifford } \\
2017\end{array}$ & NA & $\begin{array}{l}\text { Vancouver, } \\
\text { Canada }\end{array}$ & 16 & 28.8 & $\begin{array}{l}\text { Bronchial brushings } \\
\text { ( 97\% epithelial cells) }\end{array}$ & Illumina $450 \mathrm{~K}$ & $\begin{array}{l}\text { Controlled exposures to } \\
\text { diesel exhaust and allergen, } \\
\text { with filtered air and saline } \\
\text { controls }\end{array}$ \\
\hline
\end{tabular}

trimester, respectively [44]. HSD11B2 metabolizes glucocorticoids to protect the fetus from higher concentrations of maternal cortisol that may be induced by air pollution exposure [46]. Enhanced HSD11B2 promoter methylation may result in decreased HSD11B2 expression and elevated fetal cortisol exposure, potentially leading to reduced growth, as has been demonstrated for corticosteroid usage during childhood [44, 47].

Air pollution exposure could also decrease fetal growth through other mechanisms, such as through increasing maternal systolic blood pressure, as hypertension during pregnancy has been associated with lower placental blood flow and reduced nutrition delivery [48]. Living in an area with greater air pollution was associated with higher mean placental DNAm and increased systolic blood pressure that almost reached significance, relative to women with a slightly lower exposure ( $p=0.07$ with $n=50)$ [33]. However, the relationship between the different mechanisms is unclear, and none of the DNAm sites that were significantly changed were replicated between the studies by Cai et al. and Maghbooli et al. (or indeed between any of the studies described in this review) (Additional file 2: Table S2). Additional larger studies are therefore needed to shed light on the effects of specific air pollutants on DNAm and the relationship of DNAm changes with birth outcomes.

\section{Effects of air pollution on DNA methylation in children and adolescents}

The connections between air pollution, DNAm, and health are not limited to prenatal exposures and birth outcomes, but effects may persist into childhood. As an example of this, maternal $\mathrm{NO}_{2}$ exposure during the third trimester of pregnancy was associated with higher systolic blood pressure in children assessed at the age of 11 [49]. However, no relationship with blood LINE1 DNAm 
was identified with $\mathrm{NO}_{2}$ exposure. But exposure to $\mathrm{PM}_{10}$ or $\mathrm{O}_{3}$ during the first trimester was associated with lower LINE1 DNAm at birth, while $\mathrm{O}_{3}$ exposure during the third trimester was conversely associated with higher LINE1 DNAm [49]. These results highlight the effects of early life exposures and possible differences based upon both the type of pollutant and developmental stage at exposure. Such findings also suggest that the changes induced by air pollution exposure during pregnancy can persist well into childhood. A possible mechanism for the maintenance of the effects of exposure during pregnancy into childhood could be sustained changes in DNAm. However, other factors, such as genotype, may also contribute to shaping outcomes and, in some cases, may also affect DNAm. For example, $\mathrm{O}_{3}$ exposure during the first trimester in one study was associated with increased systolic blood pressure only in 11-year-old children with particular DNMT1 or DNMT3B isoforms [49]. This result suggests that variants that affect essential DNAm control genes have the potential to shape responses and health effects of environmental exposures (Fig. 1). These findings also suggest that a possible mechanism underlying modulation of DNAm following exposures could be changes in the expression of key enzymes that regulate DNAm (Fig. 1).

\section{Effects of air pollution on TET expression}

A recent study examining the impact of air pollution on other DNAm machinery found that black carbon exposure was associated with significantly higher DNAm in nasal brushings at cg23602092 in the promoter region of TET1 (Table 1 and Additional file 2: Table S2) [50]. There was also a significant association between asthma status and DNAm at this site, with lower mean methylation in asthmatic children that was also replicated in saliva and peripheral blood mononuclear cell (PBMC) samples from children in the Pediatric Environmental Exposure Study [50]. TET1 catalyzes the conversion of 5 - $\mathrm{mC}$ to 5-hmC. Higher 5-hmC levels in saliva were found in asthmatic children in comparison to non-asthmatic siblings (who had higher TET1 DNAm and would, therefore, be expected to have lower TET1 gene expression). In in vitro experiments, exposure of human bronchial epithelial cells to diesel exhaust particulate resulted in lower TET1 expression at $4 \mathrm{~h}$ and higher TET1 DNAm at $24 \mathrm{~h}$, along with significantly reduced $5-\mathrm{hmC}$ levels [50]. These results suggest that the oxidative stress associated with air pollution exposure results in time-dependent modulation of TET1 expression, which then affects 5hmC levels.

\section{Air pollution and FOXP3}

A few studies have examined the effects of air pollution exposure on DNAm in association with another specific gene, forkhead box P3 (FOXP3) [51, 52]. FOXP3 controls the differentiation and activity of $\mathrm{T}$ regulatory cells and may, therefore, have a role in diseases such as asthma [51-53]. For example, one group isolated DNA from $T$ regulatory cells in the blood of adolescents living in Fresno, California [51]. They found that FOXP3 DNAm was significantly higher in association with higher average $\mathrm{PAH}$ concentrations over 1 month, 3 months, and 1 year in asthmatics, while in non-asthmatics, higher FOXP3 DNAm was only seen with average PAH concentrations over 3 months and a year. FOXP3 DNAm was found to be inversely correlated with FOXP3 protein expression. There were also significant positive associations between PAH exposure and total IgE levels at all time points in non-asthmatics and all except 3 months in asthmatics. The effects of PAH exposure on FOXP3 DNAm and IgE were maintained in 19 volunteers who were retested 8 months after their initial visit [51].

Similar results were obtained in a study in New York City using accelerometers and personal backpack monitoring to assess the relationship between exercise, black carbon exposure, and FOXP3 DNAm in cheek swabs [52]. Analysis of FOXP3 CpGs indicated that among children with high black carbon exposure $\left(>1.21 \mu \mathrm{g} / \mathrm{m}^{3}\right)$, non-active children $(<1 \mathrm{~h}$ of moderate-to-vigorous activity a day) had the highest DNAm at FOXP3, while those who were active had $\sim 2.5 \%$ lower average methylation at specific FOXP3 sites. There was no association of physical activity with DNAm levels among children with little black carbon exposure. These results suggest that, despite potentially greater black carbon exposure due to the increased breathing associated with activity, exercise may protect against the harms of air pollution exposure on health, in part by modulating DNAm. Indeed, results also indicated a negative correlation between FOXP3 DNAm at specific CpG sites and the ratio of forced expiratory volume in $1 \mathrm{~s}$ to forced vital capacity $\left(\mathrm{FEV}_{1} /\right.$ FVC) and forced expiratory flow at $25-75 \%$ of pulmonary volume $\left(\mathrm{FEF}_{25-75 \%}\right)$, suggesting an association with lung function [52]. However, there was no correlation between FOXP3 promoter DNAm, activity or lung function, and FOXP3 mRNA expression in cheek cells. These studies suggest that air pollution exposure may induce FOXP3 methylation, which in turn may reduce FOXP3 expression (potentially reducing $\mathrm{T}$ regulatory cell function), ultimately promoting asthma morbidity.

The studies described above both concluded that air pollution affects FOXP3 DNAm, but the timeframes of exposure effects were different, with Hew et al. showing effects only when exposures were averaged over months while Lovinsky-Desir et al. showed changes over 6 days $[51,52]$. This discrepancy may reflect differences between the cell types evaluated, the effects of black carbon and PAHs (or other pollutants with which they are 
correlated), or alternative factors, such as the increased precision of a personal backpack rather than LUR-based pollution assessment. Nevertheless, these studies provide an example of how air pollution exposure could be linked to the development of diseases, such as asthma, through modulation of DNAm at key sites [54].

\section{Effects of air pollution exposure on DNA methylation in adults}

The impact of air pollution on DNAm has also been investigated in adults. It should be noted, however, that in many of these studies, early life exposures were not recorded and may influence the results seen in adult volunteers. In one study from our group, exposure to freshly generated diesel exhaust (DE) (standardized to $300 \mu \mathrm{g} / \mathrm{m}^{3}$ of $\mathrm{PM}_{2.5}$ ) for $2 \mathrm{~h}$ modulated DNAm at 2827 CpG sites in blood samples collected $30 \mathrm{~h}$ later, relative to filtered air exposure (Table 1) [55]. DE exposure induced a decrease in DNAm on average across the CpGs measured on Illumina $450 \mathrm{~K}$ chips, with substantial demethylation of promoter regions of genes in the MAPK and NF- $\mathrm{B}$ pathways. This finding suggests that DNAm changes may increase cytokine concentrations by reducing DNAm-mediated repression of inflammatory gene expression. While the link herein is speculative, increased cytokine levels are indeed often seen following controlled exposures [56].

Lower DNAm was also found in a study of older male volunteers living in Boston, which assessed the effects of exposure to PM, black carbon, and $\mathrm{O}_{3}$ on DNAm in the blood associated with five immune-related genes, including interleukin $(I L)$, coagulation factor III tissue factor (F3), interferon gamma (IFNG), and intercellular adhesion molecule (ICAM) 1 [57]. There were significant associations between the particle number in the first week or black carbon exposure in the third to fourth weeks, before blood draws with DNAm at F3. An interquartile increase in particle numbers $\left(\sim 15,000\right.$ particles per $\left.\mathrm{cm}^{3}\right)$ was associated with an 18\% decrease in F3 DNAm, although the apparent lack of cell-type correction in this study raises concern for confounding. Likewise, increased exposure to $\mathrm{O}_{3}$ in the 2- to 4-week period before clinic visits was associated with lower DNAm in the promoter region of ICAM1. A $1 \%$ decrease in ICAM1 promoter DNAm was correlated with a $0.7 \%$ increase in blood ICAM1 protein expression. These results show that air pollution exposure decreases DNAm at specific immune system-related sites and that this is associated with modulation of associated gene expression.

In a follow-up paper, Bind et al. reanalyzed their data on air pollution and DNAm, using an approach where methylation values were separated into ten quantiles according to the degree of pre-existing DNAm for each volunteer and correlation with air pollution assessed for each of these quantiles, rather than with mean DNAm across volunteers [58]. They found differences compared to the earlier analysis, including stronger negative associations between F3 DNAm and particle number in volunteers, with greater methylation at F3 (higher deciles) but with IFNG at lower deciles. There was a positive association between black carbon exposure and ICAM1 DNAm at the 90th decile of ICAM1 DNAm but negative associations with the 10th to 60th deciles. Such an approach may enhance the ability to robustly detect nuances in the effects of air pollution on DNAm.

In addition to quantile analysis, other advanced statistical methods may improve data quality and provide new insights into the relationship between air pollution and DNAm. As an example, a novel multivariate Bayesian variable selection approach was implemented on an analysis of blood DNAm data from 92 volunteers [59]. In comparison with a conventional Bayesian variable selection approach, which identified DNAm of HLA class II histocompatibility antigen, DR alpha chain (HLA-DRA), and IL 9 as being associated with mean concentrations of black carbon for the month before each blood draw, the new approach had improved sensitivity and identified $H L A-D R A$, Fc fragment of IgE receptor Ig, and IL9 in association with black carbon and IL5 and CCL11 with sulfate concentrations. Advances in the analysis may lead to greater consistency in the results obtained from studies of air pollution and DNAm, given that, as indicated in Additional file 2: Table S2, there is no consistency among the top CpGs identified in the studies reviewed.

\section{Effects of air pollution exposure averaging time and concentration}

Studies have shown that averaging air pollution measures over longer time periods often results in stronger associations with DNAm changes [30, 31, 60]. For example, one study examined $\mathrm{PM}_{2.5}$ and $\mathrm{NO}_{x}$ exposures, averaged over a full-year proceeding of blood draws, and looked at the association with DNAm in CD14 ${ }^{+}$-purified monocytes from 1264 volunteers [60]. Measurement identified five CpGs (four higher, one lower) that were associated with greater $\mathrm{PM}_{2.5}$ exposure (Additional file 2: Table S2). Another study combining several large cohorts investigating the effects of $\mathrm{PM}_{2.5}$ exposure on blood DNAm over different periods up to 28 days also showed greater effects over a longer time window of exposure [31]. Two CpGs were positively correlated with 2and 7-day average $\mathrm{PM}_{2.5}$ concentrations, respectively, across the three cohorts (Additional file 2: Table S2). But with a 28-day window, $10 \mathrm{CpGs}$ showed changes in DNAm, three of which had lower DNAm with increasing $\mathrm{PM}_{2.5}$ levels, while seven showed higher methylation [31].

The effects of $\mathrm{PM}_{2.5}$ on decreasing ICAM1-associated DNAm also seemed to increase over 1-, 7-, and 28-day 
windows in another study, suggesting that the underlying changes were slow to develop or required air pollution concentration peaks that only occur intermittently over a longer period [61]. However, the impact of $\mathrm{PM}_{2.5}$ on ICAM1 DNAm was not maintained at second study visits a few years later, suggesting (as previously shown at an even shorter interval, but less specifically [55]) that the effects of short-term air pollution exposure may not persist over multiple years [61]. These results suggest that air pollution effects on DNAm may be most visible over medium to long time windows. This time-dependent effect indicates that exposures may take some time to modulate DNAm and that DNAm changes may be maintained for extended periods or alternatively highlights the benefits of prolonged air pollution averaging periods in smoothing out concentration spikes that may lead to inconsistent results.

Air pollutant concentration, like time, may also influence the strength of the association with DNAm in adults. One study evaluated the association of $\mathrm{NO}_{x}$ exposure with PBMC DNAm in a Swedish cohort with low $\mathrm{NO}_{x}$ levels $\left(7 \mu \mathrm{g} / \mathrm{m}^{3}\right)$ and an Italian cohort with higher average air pollution $\left(\mathrm{NO}_{x} 94 \mu \mathrm{g} / \mathrm{m}^{3}\right)$ (Additional file 1: Table S1) [62]. Two CpGs on the Illumina 450K platform were associated with long-term $\mathrm{NO}_{x}$ exposure in the higher pollution cohort, but no significant effects were found in the lower pollution cohort (Additional file 2: Table S2). Similar results for $\mathrm{NO}_{x}$ were found in another study comparing cohorts from Italy $\left(93 \mu \mathrm{g} / \mathrm{m}^{3}\right)$, again with higher air pollution which was associated with lower average blood methylation across the Illumina $450 \mathrm{~K}$ platform, and the Netherlands $\left(30 \mu \mathrm{g} / \mathrm{m}^{3}\right)$ where air pollution concentrations were intermediate (between the high of Italy and the low of Sweden) which did not reach significance $[30,62]$. These results may indicate that the effects of $\mathrm{NO}_{x}$ on DNAm are concentration-dependent and suggest a possible threshold that lies somewhere between 7 and $93 \mu \mathrm{g} / \mathrm{m}^{3}$. However, it is not possible to say with certainty that effects were mediated by $\mathrm{NO}_{x}$, as in natural setting volunteers are likely to be exposed to a complex mixture of pollutants which may be produced by the same sources or otherwise correlated.

\section{Additional sources of DNA methylation variability}

Interestingly, global effects on DNAm may also be influenced by genomic context, as a negative correlation between $\mathrm{NO}_{2}$ exposure and global $450 \mathrm{~K}$ blood DNAm was found across regions of low CpG density but not in CpG islands [30]. However, conversely, a positive correlation of DNAm in gene promoter regions with higher $\mathrm{PM}_{10}$ $\left(47 \mu \mathrm{g} / \mathrm{m}^{3}\right)$ concentrations was noted in a cohort from Italy. In the Netherlands cohort, with lower $\mathrm{PM}_{10}$ levels $\left(25 \mu \mathrm{g} / \mathrm{m}^{3}\right)$, air pollution was again associated with a global decrease in $450 \mathrm{~K}$ DNAm, except on CpG islands, shores, and in gene promoter regions [30]. Another study found a significant association between personal $\mathrm{PM}_{2.5}$ exposure and DNAm at $13 \mathrm{CpGs}$, the majority of which were located in gene bodies, while seven were found in the open sea (Additional file 2: Table S2) [63]. These results may indicate that, in addition to there possibly being different thresholds at which particular air pollutants modulate global DNAm, there may also be concentration-dependent effects on DNAm at locations relative to $\mathrm{CpG}$ islands or gene promoters.

Differences between cohorts may alternatively be explained by variation in individuals over time. A recent study evaluated the link between air pollution exposures and DNAm in buccal cells over time in Leuven, Belgium [64]. They found that within-volunteer variation in DNAm and DNA hydroxymethylation over time was 16 and nine times higher, respectively, than between-volunteer variation. Exposure to $\mathrm{PM}_{2.5}$ and $\mathrm{PM}_{10}$ was associated with a decrease in both DNAm and DNA hydroxymethylation, with the largest effects found using a 7-day average exposure window. For every $5-\mu \mathrm{g} / \mathrm{m}^{3}$ increase in $\mathrm{PM}_{2.5}$ (relative to an average concentration $20 \mu \mathrm{g} / \mathrm{m}^{3}$ ), there was a $-0.53 \%$ and $-0.015 \%$ decrease in the global DNAm and DNA hydroxymethylation, respectively. Although this study used highly accurate mass spectrometry analysis, the small size of the changes makes the biological relevance of the variability seen within and between volunteers questionable. Nevertheless, while DNAm generally constitutes a more stable biomarker than mRNA or protein expression, representing a somewhat longer time window in terms of biological responses, these results indicate that there may still be significant variability within volunteers over time that could result in false-positive or negative results [57, 64]. This variability may contribute to the finding that there is no overlap in the CpGs described in the manuscripts reviewed (Additional file 2: Table S2). This variability may reflect the importance of immune system pathways, which may show greater DNAm volatility, in the response to air pollution exposure, and this may contribute to disease susceptibility differences between individuals over time [65].

\section{Association of DNA methylation with lung disease-relevant outcomes}

In addition to affecting gene expression, DNAm changes may be associated with lung disease development and exacerbation, our area of research interest. A study investigating the effects of air pollution exposure on lung function identified a significant association of $\mathrm{NO}_{2}$ exposure with blood DNAm and with lung function (FVC and $\mathrm{FEV}_{1} / \mathrm{FVC}$ ) that was borderline significant (Table 1) [66]. However, findings for $\mathrm{NO}_{2}$ with DNAm were not replicated in two independent cohorts described in the same paper [66]. Nevertheless, mediation analysis 
suggested that one and two CpG sites mediated a significant association of $\mathrm{NO}_{2}$ with $\mathrm{FVC}$ and $\mathrm{FEV}_{1} / \mathrm{FVC}$, respectively (Additional file 2: Table S2). These results indicate that DNAm modifications may act, at least in part, as an intermediary between $\mathrm{NO}_{2}$ exposure and lung function changes $\left(\mathrm{NO}_{2} \rightarrow\right.$ DNAm $\rightarrow$ lung function).

A similar analysis of volunteers in Boston showed that 28-day average exposures to $\mathrm{BC}, \mathrm{CO}, \mathrm{PM}_{2.5}$, or $\mathrm{NO}_{2}$ resulted in significantly decreased lung function, as measured by $\mathrm{FEV}_{1}$ and FVC, with this association modified by blood DNAm of the glucocorticoid receptor (NR3C1) and IL6 [29]. However, no effects on spirometry were found in association with higher LINE1 or Alu DNAm. These results suggest that DNAm at crucial sites, rather than global status, may be associated with lung function. In evaluating specific chronic obstructive pulmonary disease (COPD) phenotypes, effects of $\mathrm{BC}, \mathrm{PM}_{2.5}$, and $\mathrm{NO}_{2}$ exposure on FVC and $\mathrm{O}_{3}$ on $\mathrm{FEV}_{1}$ were greater in volunteers with emphysema, while those with chronic bronchitis had lower $\mathrm{FEV}_{1}$ values only in response to $\mathrm{PM}_{2.5}$ exposure [29]. A similar study in asthmatic and atopic volunteers investigating the effects of mono- and co-exposures to diesel exhaust and allergen showed that exposure order might contribute to the magnitude of the response [39]. A total of seven CpG sites were modulated by allergen, DE, or co-exposure in bronchial brushings at $48 \mathrm{~h}$. However, when the same lung tissue was exposed to an allergen and then to the allergen and DE a month later, $548 \mathrm{CpG}$ sites were modulated [39]. These results suggest that exposure to an allergen may prime the lungs for responsiveness, which results in more significant effects on subsequent co-exposure to air pollution and an allergen. However, the mechanisms underlying such effects at the level of DNAm are unclear.

\section{Mechanisms underlying the effects of air pollution on DNA methylation}

The papers described above highlight the fact that air pollution exposure is associated with changes in DNAm from the earliest stages of development onwards that may contribute to disease development (Table 1). However, we do not fully understand how changes in DNAm occur. In particular, we do not know to what extent systemic effects of air pollution exposure are mediated by PM translocating from the lungs into the blood rather than, as is generally predominantly thought, mediated through the movement of cytokines from the lung into circulation [46]. Regardless, oxidative stress induced by ROS is believed central to the downstream effects of inhaled air pollution (Fig. 1). Oxidative species may also reduce the expression of methionine adenosyltransferase 1A (MAT1A) and the efficiency of the one-carbon metabolism pathway leading to a scarcity of the methyl donor SAMe needed to establish and maintain DNAm (Fig. 1)
$[33,34]$. Air pollution exposure can also reduce DNMT$1 \alpha$ expression, potentially enhancing passive dilution $[18$, 33]. Such effects may, over time on balance, increase the number of unmethylated cytosine sites relative to those methylated, following air pollution exposure. A decrease in 5-mC could also be mediated by enhanced conversion of $5-\mathrm{mC}$ to $5-\mathrm{hmC}$, with subsequent conversion to 5 -fC or 5-caC followed by excision-repair (Fig. 1).

Conversely, DNAm of the TET promoter may be enhanced by exposures, potentially resulting in decreased gene and protein expression [50]. Reduced TET protein expression and activity may favor the maintenance of $5-\mathrm{mC}$ levels and, over time, promote increased methylation levels. These different mechanisms raise the suspicion that TRAP disrupts the balance between effects mediating higher DNAm and removal of methyl groups (Fig. 1). For example, changes in the overall expression of enzyme families, such as DNMT and TET, alongside processes such as oxidation and passive dilution of DNAm may lead to global hypomethylation $[13,18,19]$. It is certainly conceivable that TRAP induces more "targeted" effects on specific sites, through changes in the recruitment of transcription factors and histones that attract enzymes to mediate DNAm or demethylation, but the current evidence is too immature to portray any such targeting with sufficient consistency $[13,19]$.

\section{Intervention on air pollution-related DNA methylation}

Clues to the mechanisms underlying air pollution-induced DNAm changes may come from studies testing possible interventions, as a number of papers have indicated that the harmful effects of air pollution exposure can be reduced, though not eliminated [67-69]. Limited evidence suggests benefits of exercise and supplementation with antioxidants, vitamins, and carotenoids in reducing the effects of air pollution, but replication and large-scale validation are critically needed $[67,68]$. A recent controlled human exposure experiment tested B vitamin supplementation (B6, B12, and folic acid) to reduce the effects of air pollution exposure on DNAm in $\mathrm{CD}_{4}^{+}$Th cells (Table 1) [69]. $\mathrm{PM}_{2.5}$ exposure caused changes in DNAm that were attenuated $(28-76 \%$ in the 10 most significant CpGs) after B vitamin supplementation. B vitamins may maintain DNAm levels by supplying methyl groups through the one-carbon cycle, suggesting that this may be mechanistically important (Fig. 1). Improved studies may enable a greater understanding of the mechanisms underlying the effects of air pollution exposure on DNAm.

\section{Common limitations of the studies to date}

There are some important limiting factors in many of the papers described, including small sample sizes, low numbers of air pollution monitoring sites, variability in analysis approaches, and low reproducibility between cohorts (Table 1) [28]. Concern over the reproducibility 
of results is supported by an analysis of the CpGs in Additional file 2: Table S2, extracted from the main text of the papers reviewed. Surprisingly, no duplicate CpG sites were identified between any of the papers reviewed. While we do not know the reason(s) behind this lack of duplication, we can speculate as to a number of possibilities that appear linked to limitations of the papers reviewed. These range from variability in the environments of different studies, through differences in data analysis techniques to intrinsic stochasticity in DNA demethylation changes following air pollution exposure.

\section{Heterogeneity between studies}

In the majority of studies, exposures were inferred using LUR models based on data from fixed sensors frequently a kilometer or more from volunteer's homes [31, 57, 64]. Furthermore, LUR models do not always take into account localized exposures in areas where people spend time away from home during the day. Depending on the local source of air pollution, there are likely to be differences in the mixture of pollutants to which individuals are exposed [28]. Some studies employ measurement or statistical adjustment for different components of for example $\mathrm{PM}_{2.5}$, but the attribution of DNAm changes to particular elements remains challenging [70], possibly excepting single-component controlled human exposure studies [71]. A further limitation is that in most studies only a handful of specific pollutants were measured and the effects may actually be mediated by unmeasured air pollutants from the same source or whose concentrations correlate with the measured factors $[8,28]$. Differences may be compounded if multiple pollutants interact, as has been shown for TRAP and allergens, depending on whether these combinations result in negative, additive, or synergistic effects on DNAm [7]. Emerging data also indicate that air pollution concentrations can vary dramatically over small areas due to traffic patterns, trees, point emission sources, and terrain, which may lead to considerable inaccuracies over shorter time windows $[8,72]$. As averaging time periods evaluated in studies get longer, many spikes or troughs in air pollution concentration may be smoothed out, but controlling for other factors, such as seasonality, may become more important [28, 73]. Differences in timing between exposure and analysis may also contribute to a lack of duplication, as there may be timedependent changes in DNAm patterns in response to air pollutants.

Additional variability may be introduced by individual characteristics, including genetic background, diet, and smoking habits, although many studies try to control for such factors [57]. Nevertheless, a previous study of the effects of diet on DNAm found no significant effects of a typical western diet, as would be expected to be consumed by the majority of participants in the studies evaluated, though they did find effects of a diet high in vegetables and fruit [74]. To the extent that an observational study assessed regional air pollution that correlated substantially with local methylation-altering foods, there could be confounding of the relationship between air pollution and DNAm endpoints.

\section{Variability in analytical approaches}

A further technical limitation that may affect analysis is that most studies used bisulphite conversion and DNAm analysis without additional steps to isolate 5 -hmC modification, and results, therefore, represent both base modifications, which may have different effects on transcription [20]. The variability inherent in sampling from small cohorts may also be exacerbated by differences in preprocessing and normalization algorithms used between studies, reflecting the lack of a standard protocol for analysis of results from the majority of DNAm analysis platforms [25, 75-77]. This lack of standardization is also often present in choices regarding cutoff values, including those for outlier samples and the array signal considered to be above background. Additionally, the majority of studies we evaluated did not report performing cell type correction (Additional file 1: Table S1), based on either cell counts or estimated via algorithmic techniques from DNAm data [78], which may mean that results are biased as air pollution exposure can modulate cell type proportions [56, 79-81]. Cell type proportions have been shown to be modulated following air pollution exposure, both directly by analysis of differential cell counts $[56,79,81]$ and by indirect determination using DNAm data and Houseman or Horvath's algorithmic approaches [80]. Differences in the statistical methods used for data analysis (e.g., linear vs linear mixed-effects models), the post-tests used for multiple testing adjustment, and the choice of significance thresholds may also contribute to false-positive and negative results, hindering study replication [43].

\section{Targeting of DNA methylation changes}

The data reviewed suggest that in general, air pollution exposure mediates a decrease in DNAm across the genome, though methylation at some sites may be increased (Additional file 1: Table S1). Data from the use of drugs, such as low doses of decitabine (5-aza-2'deoxycytidine) that reduce the activity and number of DNMTs, show that treatment also leads to global hypomethylation following DNA replication [82]. This occurs via an inability of DNMTs to replicate the methylation status of sites on the DNA template strand to the daughter strand, leading to dilution of DNAm. Similar untargeted effects may underly the changes induced following air pollution exposure through 
decreased expression and activity of DNMTs (Fig. 1) [13, 19, 83]. Alternatively, decreased MAT1A or onecarbon cycle activity may mediate a shortage of SAMe, the methyl donor, leading to global decreases in average DNAm. Stochastic or untargeted effects of air pollution on DNAm would make replication rare in global analyses (especially for methyl-seq or on the $450 \mathrm{~K} / 850 \mathrm{~K}$ platforms, given the large number of sites).

The mechanisms underlying potential increases in DNAm at specific sites are less well understood [13, 19]. However, initial evidence suggests that DNMTs may use protein domains to bind to DNA in a sequence-independent manner or may be recruited to DNA sites through interactions with other proteins, including transcription factors and HDAC1, or by miRNAs. The specificity of increased DNAm following air pollution exposures and any mechanisms underlying such effects remain to be fully clarified.

\section{Unresolved questions regarding the effect of air pollution on DNA methylation}

The previous sections suggest a range of foci in which uncertainty remains to be resolved, and other deficiencies in the literature are worth noting here [83]. For example, the extent to which exposures during specific developmental stages are most influential, relative to effects observed in relation to accumulated changes over prolonged periods, may have profound implications. Also, worth interrogation is whether or not there is a threshold concentration (or time-concentration product) of pollution that must be exceeded to be sufficient for a demonstrable health effect. Whatever the observed impact on DNAm, it would be valuable to know which particular elements of the air pollution mixture most potently drive such effects. It is also unclear whether changes in DNAm are due to global perturbations of enzymes such as TET or, if instead, effects are predominantly targeted to individual genes (Fig. 1 and Table 1) [19].

A further crucial unresolved question in environmental epigenetics is how changes in DNAm observed with acute exposures relate to the development of morbidity years later [84]. Typically, chronic exposures are assigned based on an average or other summarizing metrics, which inevitably reflects a series of shorter-term exposures that can be presumed to act cumulatively. In some, but certainly not all cases, changes in DNAm that correlate with long-term exposures are also altered by short-term exposure; a noteworthy example in the context of TRAP was recently exhibited [85], but few of such comparative attempts have been documented in humans. In a fish model comparing acute and chronic stress, $27 \%$ of the acute stress-induced changes in DNAm were also seen in response to chronic stress [86]. However, DNAm is reversible [87], and a controlled human study [55] demonstrated that circulating changes in DNAm observed within $30 \mathrm{~h}$ of acute exposure to TRAP alone did not carry over to a re-examination weeks later. A similar phenomenon was observed more recently in mice [88]. Since DNAm changes associated with TRAP may be at least in part remediable by acutely targeted interventions, our understanding of the temporal dynamics linking TRAP to longstanding and functionally relevant DNAm requires more investigation.

\section{Conclusions}

DNAm is both static and dynamic, with cell-type specific patterns maintained throughout life, and environmental exposures may mediate alterations in both gene-specific and average DNAm [33, 61]. Air pollution exposure is associated with changes in DNAm across the life course, from early effects during pregnancy through to old age. Often effects on DNAm in adulthood seem most apparent in association with longer periods of exposure, suggesting that changes take time or need to accumulate, but data for temporal resolution therein remains poorly developed, and it is possible that short-term peaks have long-term effects [39]. It remains unclear if effects are accelerated by early life air pollution exposure or whether disease development simply reflects cumulative exposures. The specific mechanisms through which air pollution modulates DNAm and ultimately causes disease are poorly described. An improved understanding of the mechanisms underlying the effects of air pollution exposure may allow more targeted preventative and remedial strategies.

As we better understand how changes in DNAm are associated with effects on health, we will better differentiate between causal associations, confounding in which another factor is primarily causative of change in DNAm and downstream morbidity, or even reverse causation, in which disease processes alter DNAm (Byrne and Drake 2019). Ultimately improved knowledge of how air pollution exposures lead to changes in DNAm and thus contribute to the risk of developing lung conditions, cardiovascular disease, and mental health disorders may enable preventative strategies to minimize the development of these chronic conditions.

\section{Additional files}

Additional file 1: Table S1. Enhanced detail on the studies reviewed. This table describes details of the studies described in this review, including the first author's surname, study location, age and number of volunteers, concentrations of various air pollutants, sample types, and study details. NA, not applicable; ND, not determined; NR, not reported; BC, black carbon; CO, carbon monoxide; LINE, long interspersed nuclear element; LUR, land use regression; $\mathrm{NO}$, nitric oxide; $\mathrm{NO}_{2}$, nitrogen dioxide $\mathrm{NO}_{x}$, nitrogen oxides; $\mathrm{O}_{3}$, ozone; $\mathrm{PM}$, particulate matter; $\mathrm{PM}_{2.5}$, particulate matter smaller than $2.5 \mu \mathrm{m}$; $\mathrm{PM}_{10}$, particulate matter smaller than $10 \mu \mathrm{m}$; $\mathrm{PAH}$, polycyclic aromatic hydrocarbon. (XLSX 21 kb) 
Additional file 2: Table S2. List of top air pollution-associated $\mathrm{CpG}$ site numbers. The main text of the papers highlighted in Table 1 was checked for lists of specific cg sites. All the cg sites were collated and ranked according to the cg number. Annotation details for the CpGs, including chromosome and location, strand, relation to $\mathrm{CpG}$ islands, gene symbol, and relation to genes, were merged from Illumina EPIC annotation data produced by the Kasper D. Hansen lab (www.hansenlab.org). TSS, transcription start site; UTR, untranslated region. (XLSX $21 \mathrm{~kb})$

\section{Abbreviations}

5-caC: 5-Carboxycyotosine; 5-fC: 5-Formylcytosine; 5-hmC: 5Hydroxymethylcytosine; 5-mC: 5-Methylcytosine; AP-1: Activator protein-1; BAL: Bronchioalveolar lavage; BC: Black carbon; CD: Cluster of differentiation; CO: Carbon monoxide; COPD: Chronic obstructive pulmonary disease; DALYs: Disability-adjusted life years; DE: Diesel exhaust; DEP: Diesel exhaust particulate; DNA: Deoxyribonucleic acid; DNAm: DNA methylation; DNMT: DNA methyltransferase; F3: Coagulation factor III tissue factor; $\mathrm{FEF}_{25-}$ 75: Forced expiratory flow at $25-75 \%$ of the pulmonary volume; $F_{1} V_{1}$ : Forced expiratory volume in 1 second; FOXP3: Forkhead box P3; FVC: Forced vital capacity; $\mathrm{H}_{2} \mathrm{O}_{2}$ : Hydrogen peroxide; HLA-DRA: HLA class II histocompatibility antigen, DR alpha chain; HSD11B: Hydroxysteroid 11-beta dehydrogenase; ICAM: Intercellular adhesion molecule; IFN: Interferon; IL: Interleukin; IUGR: Intrauterine growth restriction; LINE: Long interspersed nuclear element; LUR: Land use regression; MAPK: Mitogen-activated protein kinase; MAT1A: Methionine adenosyltransferase 1A; miRNA: MicroRNA; NFKB: Nuclear factor-kappa; NO: Nitric oxide; $\mathrm{NO}_{2}$ : Nitrogen dioxide; $\mathrm{NO}_{x}$ : Nitrogen oxides; $\mathrm{O}_{3}$ : Ozone; PAH: Polycyclic aromatic hydrocarbon: PM: Particulate matter; $\mathrm{PM}_{0.1}$ : Ultrafine particulate matter; $\mathrm{PM}_{10}$ : Particulate matter smaller than $10 \mu \mathrm{m}$; $\mathrm{PM}_{2.5}$ : Particulate matter smaller than $2.5 \mu \mathrm{m}$; ROS: Reactive oxygen species; SAMe: S-Adenosyl methionine; SLC25A28: Solute carrier family 25 member 28; $\mathrm{SO}_{2}$ : Sulfur dioxide; TDG: Thymine DNA glycosylase; TET: Ten-eleven translocation methylcytosine dioxygenase; TPO: Thyroid peroxidase; TRAP: Traffic-related air pollution; WHO: World Health Organization

\section{Acknowledgements}

The authors would like to thank Drs. Meaghan J. Jones, Hang (Hannah) Li, and Amy Polster for their helpful comments, which substantially improved this manuscript.

\section{Authors' contributions}

Drs. CFR and CC wrote and edited the manuscript, tables, and figure. Both authors read and approved the final manuscript.

\section{Funding}

This work was supported by the BC Lung Association, the Canada Research Chairs program, the Canadian Institutes of Health Research (CIHR), Mitacs through the Mitacs-Accelerate program, and the Michael Smith Foundation for Health Research (MSFHR).

\section{Availability of data and materials}

All data reviewed and described is either included in this manuscript or available online in the relevant publications.

\section{Ethics approval and consent to participate}

Not applicable.

\section{Consent for publication}

All authors have contributed to this study and approve its submission.

\section{Competing interests}

The authors declare that they have no competing interest.

\section{Author details}

${ }^{1}$ Respiratory Medicine, Faculty of Medicine, Chan-Yeung Centre for Occupational and Environmental Respiratory Disease (COERD), University of British Columbia, Vancouver, British Columbia, Canada. ${ }^{2}$ Diamond Health Care Centre 7252, 2775 Laurel Street, Vancouver, BC V5Z 1 M9, Canada. ${ }^{3}$ Institute for Heart and Lung Health, University of British Columbia,
Vancouver, British Columbia, Canada. ${ }^{4}$ School of Population and Public Health, University of British Columbia, Vancouver, British Columbia, Canada.

Received: 25 March 2019 Accepted: 22 July 2019

Published online: 03 September 2019

\section{References}

1. Schraufnagel DE, Balmes JR, Cowl CT, Matteis SD, Jung S-H, Mortimer K, et al. Air pollution and noncommunicable diseases: a review by the Forum of International Respiratory Societies' Environmental Committee, Part 2: Air Pollution and Organ Systems. Chest. 2019;155:417-26.

2. Philip S, Martin RV, van Donkelaar A, Lo JW-H, Wang Y, Chen D, et al. Global chemical composition of ambient fine particulate matter for exposure assessment. Environ Sci Technol. 2014;48:13060-8.

3. Reşitoğlu IA, Altinișik $K$, Keskin A. The pollutant emissions from diesel-engine vehicles and exhaust aftertreatment systems. Clean Technol Environ Policy. 2015;17:15-27.

4. Xing J, Mathur R, Pleim J, Hogrefe C, Gan C-M, Wong DC, et al. Observations and modeling of air quality trends over 1990-2010 across the Northern Hemisphere: China, the United States and Europe. Atmospheric Chem Phys. 2015;15:2723-47.

5. Guarnieri M, Balmes JR. Outdoor air pollution and asthma. Lancet. 2014;383: 1581-92.

6. US EPA O. Ground-level Ozone Basics. US EPA. 2015 [cited 2019 Mar 18] Available from: https://www.epa.gov/ground-level-ozone-pollution/groundlevel-ozone-basics.

7. Carlsten C, Rider CF. Traffic-related air pollution and allergic disease: an update in the context of global urbanization. Curr Opin Allergy Clin Immunol. 2017;17:85-9.

8. Xie $Y$, Zhao B, Zhang L, Luo R. Spatiotemporal variations of PM2.5 and PM10 concentrations between 31 Chinese cities and their relationships with SO2, NO2, CO and O3. Particuology. 2015;20:141-9.

9. Feng S, Gao D, Liao F, Zhou F, Wang X. The health effects of ambient PM2.5 and potential mechanisms. Ecotoxicol Environ Saf. 2016;128:67-74.

10. Kelly FJ, Fussell JC. Air pollution and public health: emerging hazards and improved understanding of risk. Environ Geochem Health. 2015;37: 631-49.

11. Shukla A, Bunkar N, Kumar R, Bhargava A, Tiwari R, Chaudhury K, et al. Air pollution associated epigenetic modifications: transgenerational inheritance and underlying molecular mechanisms. Sci Total Environ. 2019;656:760-77.

12. Moen EL, Mariani CJ, Zullow H, Jeff-Eke M, Litwin E, Nikitas JN, et al. New themes in the biological functions of 5-methylcytosine and 5hydroxymethylcytosine. Immunol Rev. 2015;263:36-49.

13. Lamadema N, Burr S, Brewer AC. Dynamic regulation of epigenetic demethylation by oxygen availability and cellular redox. Free Radic Biol Med. 2019:131:282-98.

14. Edgar R, Tan PPC, Portales-Casamar E, Pavlidis P. Meta-analysis of human methylomes reveals stably methylated sequences surrounding $\mathrm{CpG}$ islands associated with high gene expression. Epigenetics Chromatin. 2014;7:28.

15. Lev Maor G, Yearim A, Ast G. The alternative role of DNA methylation in splicing regulation. Trends Genet. 2015;31:274-80.

16. Tirado-Magallanes R, Rebbani K, Lim R, Pradhan S, Benoukraf T. Whole genome DNA methylation: beyond genes silencing. Oncotarget. 2017;8: 5629-37.

17. Yang X, Han H, De Carvalho DD, Lay FD, Jones PA, Liang G. Gene body methylation can alter gene expression and is a therapeutic target in cancer. Cancer Cell. 2014:26:577-90.

18. Gowher H, Jeltsch A. Mammalian DNA methyltransferases: new discoveries and open questions. Biochem Soc Trans. 2018:46:1191-202.

19. Ficz G. New insights into mechanisms that regulate DNA methylation patterning. J Exp Biol. 2015:218:14-20.

20. Kurdyukov S, Bullock M. DNA Methylation analysis: choosing the right method. Biology. 2016;5:3.

21. Plongthongkum N, Diep DH, Zhang K. Advances in the profiling of DNA modifications: cytosine methylation and beyond. Nat Rev Genet. 2014;15:647-61.

22. Skvortsova K, Zotenko E, Luu P-L, Gould CM, Nair SS, Clark SJ, et al. Comprehensive evaluation of genome-wide 5-hydroxymethylcytosine profiling approaches in human DNA. Epigenetics Chromatin. 2017:10:16.

23. Li L, Gao Y, Wu Q, Cheng ASL, Yip KY. New guidelines for DNA methylome studies regarding 5-hydroxymethylcytosine for understanding transcriptional regulation. Genome Res. 2019;29:543-53. 
24. Lisanti S, Omar WAW, Tomaszewski B, Prins SD, Jacobs G, Koppen G, et al. Comparison of methods for quantification of global dna methylation in human cells and tissues. PLoS One. 2013;8:e79044.

25. McEwen LM, Jones MJ, Lin DTS, Edgar RD, Husquin LT, Maclsaac JL, et al. Systematic evaluation of DNA methylation age estimation with common preprocessing methods and the Infinium MethylationEPIC BeadChip array. Clin Epigenetics. 2018;10:123.

26. Zhou W, Laird PW, Shen H. Comprehensive characterization, annotation and innovative use of Infinium DNA methylation BeadChip probes. Nucleic Acids Res. 2017:45:e22

27. Thomas D. Gene-environment-wide association studies: emerging approaches. Nat Rev Genet. 2010;11:259-72.

28. Hoek G, Beelen R, de Hoogh K, Vienneau D, Gulliver J, Fischer P, et al. A review of land-use regression models to assess spatial variation of outdoor air pollution. Atmos Environ. 2008:42:7561-78.

29. Lepeule J, Bind M-AC, Baccarelli AA, Koutrakis P, Tarantini L, Litonjua A, et al. Epigenetic influences on associations between air pollutants and lung function in elderly men: the Normative Aging Study. Environ Health Perspect. 2014;122:566-72.

30. Plusquin M, Guida F, Polidoro S, Vermeulen R, Raaschou-Nielsen O, Campanella G, et al. DNA methylation and exposure to ambient air pollution in two prospective cohorts. Environ Int. 2017;108:127-36.

31. Panni T, Mehta AJ, Schwartz JD, Baccarelli AA, Just AC, Wolf K, et al. Genome-wide analysis of dna methylation and fine particulate matter air pollution in three study populations: KORA F3, KORA F4, and the Normative Aging Study. Environ Health Perspect. 2016;124:983-90.

32. Motta V, Bonzini M, Grevendonk L, lodice S, Bollati V. Epigenetics applied to epidemiology: investigating environmental factors and lifestyle influence on human health. Med Lav. 2017;108:10-23.

33. Maghbooli Z, Hossein-Nezhad A, Adabi E, Asadollah-Pour E, Sadeghi M, Mohammad-Nabi S, et al. Air pollution during pregnancy and placental adaptation in the levels of global DNA methylation. PloS One. 2018;13:e0199772.

34. Goodrich JM, Reddy P, Naidoo RN, Asharam K, Batterman S, Dolinoy DC. Prenatal exposures and DNA methylation in newborns: a pilot study in Durban, South Africa. Environ Sci Process Impacts. 2016;18:908-17.

35. Hajat A, Hsia C, O'Neill MS. Socioeconomic disparities and air pollution exposure: a global review. Curr Environ Health Rep. 2015;2:440-50.

36. Birger N, Gould T, Stewart J, Miller MR, Larson T, Carlsten C. The Air Pollution Exposure Laboratory (APEL) for controlled human exposure to diese exhaust and other inhalants: characterization and comparison to existing facilities. Inhal Toxicol. 2011;23:219-25.

37. McDonnell WF. Utility of controlled human exposure studies for assessing the health effects of complex mixtures and indoor air pollutants. Environ Health Perspect. 1993;101:199-203.

38. Wellek S, Blettner M. On the proper use of the crossover design in clinical trials. Dtsch Ärztebl Int. 2012;109:276-81.

39. Clifford RL, Jones MJ, Maclsaac JL, McEwen LM, Goodman SJ, Mostafavi S, et al. Inhalation of diesel exhaust and allergen alters human bronchial epithelium DNA methylation. J Allergy Clin Immunol. 2017;139:112-21.

40. Kuh D, Ben-Shlomo Y, Lynch J, Hallqvist J, Power C. Life course epidemiology. J Epidemiol Community Health. 2003:57:778-83.

41. Gruzieva O, Xu C-J, Breton CV, Annesi-Maesano I, Antó JM, Auffray C, et al. Epigenome-wide meta-analysis of methylation in children related to prenatal NO2 air pollution exposure. Environ Health Perspect. 2017;125:104-10.

42. Kingsley SL, Eliot MN, Whitsel EA, Huang Y-T, Kelsey KT, Marsit CJ, et al. Maternal residential proximity to major roadways, birth weight, and placental DNA methylation. Environ Int. 2016;92-93:43-9.

43. Horgan GW, Chua S-P. Statistical methods for methylation data. In: Haggarty P, Harrison K, editors. Popul Epigenetics Methods Protoc. New York: Springer New York; 2017 [cited 2019 Jun 28]. p. 185-203. Available from: https://doi org/10.1007/7651_2015_316

44. Cai J, Zhao Y, Liu P, Xia B, Zhu Q, Wang X, et al. Exposure to particulate air pollution during early pregnancy is associated with placental DNA methylation. Sci Total Environ. 2017:607-608:1103-8.

45. Klepac P, Locatelli I, Korošec S, Künzli N, Kukec A. Ambient air pollution and pregnancy outcomes: a comprehensive review and identification of environmental public health challenges. Environ Res. 2018;167:144-59.

46. Rider CF, Carlsten C. Air pollution and resistance to inhaled glucocorticoids: evidence, mechanisms and gaps to fill. Pharmacol Ther. 2019;194:1-21.

47. Ohn M, Jaffe A, Selvadurai H. Persistent growth effects of inhaled corticosteroids. J Paediatr Child Health. 2016;52:964-6.
48. Burris $\mathrm{HH}$, Baccarelli AA. Air pollution and in utero programming of poor fetal growth. Epigenomics. 2017;9:213-6.

49. Breton CV, Yao J, Millstein J, Gao L, Siegmund KD, Mack W, et al. Prenatal air pollution exposures, DNA methyl transferase genotypes, and associations with newborn LINE1 and Alu methylation and childhood blood pressure and carotid intima-media thickness in the children's health study. Environ Health Perspect. 2016;124:1905-12.

50. Somineni HK, Zhang X, Biagini Myers JM, Kovacic MB, Ulm A, Jurcak N, et al. Ten-eleven translocation 1 (TET1) methylation is associated with childhood asthma and traffic-related air pollution. J Allergy Clin Immunol. 2016;137: 797-805.e5.

51. Hew KM, Walker Al, Kohli A, Garcia M, Syed A, McDonald-Hyman C, et al. Childhood exposure to ambient polycyclic aromatic hydrocarbons is linked to epigenetic modifications and impaired systemic immunity in T cells. Clin Exp Allergy J Br Soc Allergy Clin Immunol. 2015;45:238-48.

52. Lovinsky-Desir S, Jung KH, Jezioro JR, Torrone DZ, de Planell-Saguer M, Yan $B$, et al. Physical activity, black carbon exposure, and DNA methylation in the FOXP3 promoter. Clin Epigenet. 2017;9:65.

53. Li MO, Rudensky AY. T cell receptor signalling in the control of regulatory $T$ cell differentiation and function. Nat Rev Immunol. 2016;16:220-33.

54. Alexis NE, Carlsten C. Interplay of air pollution and asthma immunopathogenesis: a focused review of diesel exhaust and ozone. Int Immunopharmacol. 2014;23: 347-55.

55. Jiang R, Jones MJ, Sava F, Kobor MS, Carlsten C. Short-term diesel exhaust inhalation in a controlled human crossover study is associated with changes in DNA methylation of circulating mononuclear cells in asthmatics. Part Fibre Toxicol. 2014;11:71

56. Carlsten C, Blomberg A, Pui M, Sandstrom T, Wong SW, Alexis N, et al. Diesel exhaust augments allergen-induced lower airway inflammation in allergic individuals: a controlled human exposure study. Thorax. 2016;71:35-44.

57. Bind M-A, Lepeule J, Zanobetti A, Gasparrini A, Baccarelli AA, Coull BA, et al. Air pollution and gene-specific methylation in the Normative Aging Study. Epigenetics. 2014;9:448-58.

58. Bind M-AC, Coull BA, Peters A, Baccarelli AA, Tarantini L, Cantone L, et al. Beyond the Mean: Quantile Regression to Explore the Association of Air Pollution with Gene-Specific Methylation in the Normative Aging Study. Environ Health Perspect. 2015;123:759-65.

59. Lee KH, Tadesse MG, Baccarelli AA, Schwartz J, Coull BA. Multivariate Bayesian variable selection exploiting dependence structure among outcomes: application to air pollution effects on DNA methylation. Biometrics. 2017;73:232-41.

60. Chi GC, Liu Y, MacDonald JW, Barr RG, Donohue KM, Hensley MD, et al. Long-term outdoor air pollution and DNA methylation in circulating monocytes: results from the Multi-Ethnic Study of Atherosclerosis (MESA). Environ Health Glob Access Sci Source. 2016;15:119.

61. Peng C, Bind M-AC, Colicino E, Kloog I, Byun H-M, Cantone L, et al. Particulate air pollution and fasting blood glucose in nondiabetic individuals: associations and epigenetic mediation in the Normative Aging Study, 2000-2011. Environ Health Perspect. 2016;124:1715-21.

62. Mostafavi N, Vlaanderen J, Portengen L, Chadeau-Hyam M, Modig L, Palli D, et al. Associations between genome-wide gene expression and ambient nitrogen oxides. Epidemiol Camb Mass. 2017;28:320-8.

63. Mostafavi N, Vermeulen R, Ghantous A, Hoek G, Probst-Hensch N, Herceg Z, et al. Acute changes in DNA methylation in relation to $24 \mathrm{~h}$ personal air pollution exposure measurements: a panel study in four European countries. Environ Int. 2018;120:11-21.

64. De Nys S, Duca R-C, Nawrot T, Hoet P, Van Meerbeek B, Van Landuyt KL, et al. Temporal variability of global DNA methylation and hydroxymethylation in buccal cells of healthy adults: association with air pollution. Environ Int. 2018:111:301-8.

65. Palumbo D, Affinito O, Monticelli A, Cocozza S. DNA Methylation variability among individuals is related to CpGs cluster density and evolutionary signatures. BMC Genomics. 2018;19:229.

66. de F C Lichtenfels AJ, van der Plaat DA, de Jong K, van Diemen CC, Postma DS, Nedeljkovic I, et al. Long-term air pollution exposure, genome-wide DNA methylation and lung function in the LifeLines cohort study. Environ Health Perspect. 2018;126:027004

67. Carlsten C, MacNutt MJ, Zhang Z, Sava F, Pui MM. Anti-oxidant Nacetylcysteine diminishes diesel exhaust-induced increased airway responsiveness in person with airway hyper-reactivity. Toxicol Sci. 2014;139: 479-87. 
68. Whyand T, Hurst JR, Beckles M, Caplin ME. Pollution and respiratory disease: can diet or supplements help? A review. Respir Res. 2018;19:79.

69. Zhong J, Karlsson O, Wang G, Li J, Guo Y, Lin X, et al. B vitamins attenuate the epigenetic effects of ambient fine particles in a pilot human intervention trial. Proc Natl Acad Sci U S A. 2017;114:3503-8.

70. Wyzga RE, Rohr AC. Long-term particulate matter exposure: attributing health effects to individual PM components. J Air Waste Manag Assoc. 2015; 65:523-43.

71. National Academies of Sciences, Engineering, and Medicine, Division on Earth and Life Studies, Board on Environmental Studies and Toxicology, Committee on Assessing Toxicologic Risks to Human Subjects Used in Controlled Exposure Studies of Environmental Pollutants. Controlled Human Inhalation-Exposure Studies at EPA. Washington (DC): National Academies Press (US); 2017 [cited 2019 Jul 2]. Available from: http://www.ncbi.nlm.nih. gov/books/NBK436085/.

72. Sicard P, Agathokleous E, Araminiene V, Carrari E, Hoshika Y, De Marco A, et al. Should we see urban trees as effective solutions to reduce increasing ozone levels in cities? Environ Pollut. 2018;243:163-76.

73. Dons E, Van Poppel M, Int Panis L, De Prins S, Berghmans P, Koppen G, et al. Land use regression models as a tool for short, medium and long term exposure to traffic related air pollution. Sci Total Environ. 2014;476-477:378-86.

74. Zhang FF, Morabia A, Carroll J, Gonzalez K, Fulda K, Kaur M, et al. Dietary patterns are associated with levels of global genomic DNA methylation in a cancer-free population 12. J Nutr. 2011;141:1165-71.

75. Wang T, Guan W, Lin J, Boutaoui N, Canino G, Luo J, et al. A systematic study of normalization methods for Infinium 450K methylation data using whole-genome bisulfite sequencing data. Epigenetics. 2015;10:662-9.

76. Pidsley R, Y Wong CC, Volta M, Lunnon K, Mill J, Schalkwyk LC. A datadriven approach to preprocessing Illumina $450 \mathrm{~K}$ methylation array data. BMC Genomics. 2013;14:293.

77. Pidsley R, Zotenko E, Peters TJ, Lawrence MG, Risbridger GP, Molloy P, et al. Critical evaluation of the Illumina MethylationEPIC BeadChip microarray for whole-genome DNA methylation profiling. Genome Biol. 2016;17:208.

78. Houseman EA, Accomando WP, Koestler DC, Christensen BC, Marsit CJ, Nelson $\mathrm{HH}$, et al. DNA methylation arrays as surrogate measures of cell mixture distribution. BMC Bioinformatics. 2012;13:86.

79. Brüske I, Hampel R, Socher MM, Rückerl R, Schneider A, Heinrich J, et al. Impact of ambient air pollution on the differential white blood cell count in patients with chronic pulmonary disease. Inhal Toxicol. 2010;22:245-52.

80. Gao X, Colicino E, Shen J, Kioumourtzoglou M-A, Just AC, Nwanaji-Enwerem JC, et al. Impacts of air pollution, temperature, and relative humidity on leukocyte distribution: an epigenetic perspective. Environ Int. 2019;126:395-405.

81. Steenhof M, Janssen NAH, Strak M, Hoek G, Gosens I, Mudway IS, et al. Air pollution exposure affects circulating white blood cell counts in healthy subjects: the role of particle composition, oxidative potential and gaseous pollutants - the RAPTES project. Inhal Toxicol. 2014;26:141-65.

82. Hackanson B, Daskalakis M. Decitabine. In: Martens UM, editor. Small Mol Oncol. Berlin, Heidelberg: Springer Berlin Heidelberg; 2014 [cited 2019 Jun 27 ]. p. 269-297. Available from: https://doi.org/10.1007/978-3-642-54490-3_18

83. Alfano R, Herceg Z, Nawrot TS, Chadeau-Hyam M, Ghantous A, Plusquin M. The impact of air pollution on our epigenome: how far is the evidence? (A systematic review). Curr Environ Health Rep. 2018:5:544-78.

84. Yang IV, Lozupone CA, Schwartz DA. The environment, epigenome, and asthma. J Allergy Clin Immunol. 2017;140:14-23.

85. Gref A, Merid SK, Gruzieva O, Ballereau S, Becker A, Bellander T, et al. Genomewide interaction analysis of air pollution exposure and childhood asthma with functional follow-up. Am J Respir Crit Care Med. 2016;195:1373-83.

86. Webster TMU, Rodriguez-Barreto D, Martin SAM, Oosterhout CV, OrozcoterWengel $\mathrm{P}$, Cable J, et al. Contrasting effects of acute and chronic stress on the transcriptome, epigenome, and immune response of Atlantic salmon. Epigenetics. 2018;13:1191-207.

87. Ramchandani S, Bhattacharya SK, Cervoni N, Szyf M. DNA methylation is a reversible biological signal. Proc Natl Acad Sci. 1999;96:6107-12

88. Li Z, Li N, Guo C, Li X, Qian Y, Yang Y, et al. The global DNA and RNA methylation and their reversal in lung under different concentration exposure of ambient air particulate matter in mice. Ecotoxicol Environ Saf. 2019;172:396-402.

\section{Publisher's Note}

Springer Nature remains neutral with regard to jurisdictional claims in published maps and institutional affiliations.

Ready to submit your research? Choose BMC and benefit from:

- fast, convenient online submission

- thorough peer review by experienced researchers in your field

- rapid publication on acceptance

- support for research data, including large and complex data types

- gold Open Access which fosters wider collaboration and increased citations

- maximum visibility for your research: over $100 \mathrm{M}$ website views per year

At BMC, research is always in progress.

Learn more biomedcentral.com/submissions 